\section{How do we improve training in pulmonary physiology and the interpretation of lung function tests?}

\author{
Gerrard Phillips
}

Many years ago, pulmonary physiology and pathophysiology were central to practice, training and research in respiratory medicine. Many of the 'big names' in respiratory medicine were experts in pulmonary physiology. A quick canter through the 'further reading' section of my old, 1985, third edition of John West's 'Respiratory Physiology-the essentials' reveals names such as JE (John) Cotes, NB (Neil) Pride, EJM (Moran) Campbell, doyens of respiratory medicine in their time, but now probably unfamiliar to the young respiratory physicians of today. And I remember attending amazingly erudite lectures given by the revered David Dennison at the Brompton Hospital, when I was a senior registrar there. In modern respiratory medicine training, however, pulmonary physiology competes with so many other-potentially more interesting (?)-topics that it often receives relatively scant attention. This may be in part due to the disease-oriented approach to the practice of medicine today. However, as many readers will know, patients usually don't present with a disease label. Even today, the majority of patients presenting to the general respiratory clinic come with the non-specific symptoms of breathlessness, cough and chest pain, along with a plea from their General Practitioner, to 'sort them out.' In this context, I would argue that an understanding of respiratory physiology/pathophysiology and of lung function testing and its interpretation is still essential.

So why has this subject seemingly been relegated from the premier league of importance in our specialty? There are, I believe, a number of reasons. First, the current curriculum is packed with areas to master, so competition for attention may be one factor. This may worsen when higher specialty training in respiratory and internal medicine changes from 5 to 4 years in a few years' time, in response to the challenges posed by the 2013 Shape

Royal College of Physicians, London, UK

Correspondence to Dr Gerrard Phillips, Department of Respiratory Medicine, Dorset County Hospital, Dorchester, Dorset DT1 2JY, UK; gerrard.phillips@dchft. nhs.uk of Training report, which called for 'more doctors who are capable of providing general care in broad specialities across a range of settings.' Second, the subject may appear less exciting than some other areas of the specialty. And thirdly, it can be quite difficult to master, especially the more advanced areas such as pulmonary exercise physiology and testing.

The current UK Respiratory Medicine curriculum was written in 2010 and last amended in 2014. The requirements for Respiratory Physiology and Lung Function Testing in section F2 are, in some ways, quite lightly posited. 'Trainees must have knowledge and experience of all lung function tests. They should be competent in performing simple lung function tests and have experience of the performance of more complex tests.' No specific minimum time in a lung function laboratory is stated; trainees should simply 'spend some dedicated time in the lung function laboratory and in supervised reporting of lung function test results.' The 2008 European respiratory curriculum similarly avoids stating a minimum time. Of course, in defence of this, we are in an era of competency-based outcomes in education and training.

So how do UK trainee respiratory physicians fare in this subject area? This is difficult to gauge, but we do have one data source-how trainees perform in the specialty certificate exam (SCE). On average, there are 20 questions on this topic in the 200 question SCE (25 if sleep-related disorders are included). The data for the 4-year period, 2011-2014, are shown in figure 1 . It would appear that only $60 \%$ of UK trainees pass all the questions on respiratory physiology and lung function. So, how might this be improved?

In 2014, Patout and colleagues undertook a study to determine the ability of French respiratory medicine trainees in the interpretation of lung function testing and to correlate this with the nature of their training in the subject, in particular to whether or not they had undertaken an internship in a lung function laboratory. ${ }^{1}$ The participants completed a three-part questionnaire on their training and then undertook an assessment which consisted of five multiple choice questions (MCQs) plus short written answers to five clinical scenarios. Of the 257 trainees who responded to the questionnaire, only 41 (16\%) had done an internship in a lung function laboratory. In a multivariate analysis, the factors associated with the greatest improvement in test score were the duration of respiratory medicine training and an internship in a lung function laboratory, with the latter having the greatest influence. This suggests added value from focused training.

So does this have implications for the UK? How might we improve both the profile of this subject and the ability of our trainees in it? The British Thoracic Society (BTS) and the Association for Respiratory Technology and Physiology (UK)(ARTP) have jointly produced and run a 'short course' on pulmonary physiology in each of the last 3 years and the BTS summer meeting session 'Preparing

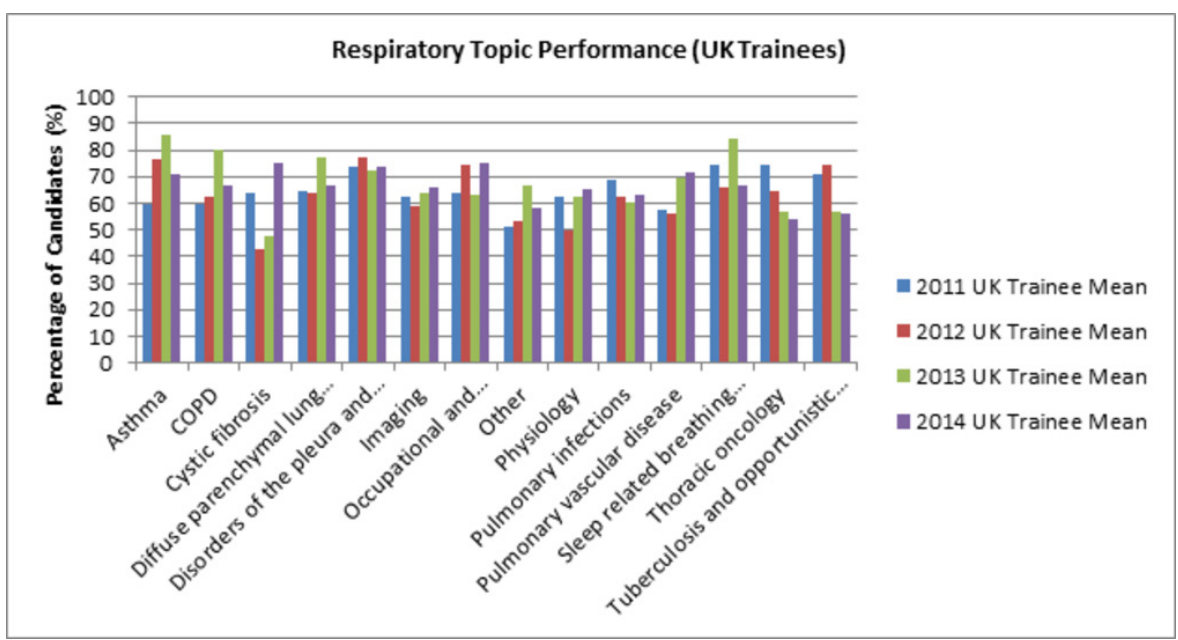

Figure 1 Respiratory topic performance (UK Trainees). 
for the Respiratory SCE' usually includes a section and a quiz on the topic. With the likelihood of increased time pressure on the UK curriculum, is it realistic (or even desirable) to specify a minimum time in a lung function laboratory? Indeed, could this be equitably achieved? Should we specify attendance at designated courses? Should we consider 'boot camps' as Health Education England has suggested for the more 'craft' elements of training? Or, since exams drive training, should we simply use the SCE to further lever the situation?

I believe that we need to plan for the future-now. If the new 3-year stage 1 training programme for Internal Medicine is introduced in August 2019, as seems likely, the first cohort of trainees recruited into a new 4-year training programme in Respiratory and Internal Medicine will start in August 2022. So we have 4-5 years to address the respiratory physiology/lung function (and other topic) training issue(s). I think this is best undertaken on a regional basis, and with a focused approach. Perhaps, specialty training committees could identify several preferred lung function laboratories in their regions (particularly acknowledging the quality of their training offer) and ensure that all their trainees spend, early in their training, at least 5-10 working days (open to discussion) gaining specific dedicated training in them? And perhaps one or two trainers at each trust could lead to ensure that this basic training is developed further in the clinical workplace and related to clinical material? Curriculum-associated documents could be produced to guide and support this.

Competing interests None declared.

Provenance and peer review Commissioned; externally peer reviewed.

(C) Article author(s) (or their employer(s) unless otherwise stated in the text of the article) 2018. All rights reserved. No commercial use is permitted unless otherwise expressly granted.

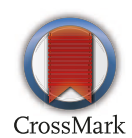

To cite Phillips G. Thorax 2018;73:2-3.

Published Online First 17 October 2017

\section{Linked}

http://dx.doi.org/10.1136/thoraxjnl-2016-209136

Thorax 2018;73:2-3.

doi:10.1136/thoraxjnl-2017-210140

\section{REFERENCE}

1 Patout M, Sesé L, Gille T, et al. Does training respiratory physicians in clinical respiratory physiology and interpretation of pulmonary function tests improve core knowledge? Thorax 2018;73:78-81. 